\title{
Booderee National Park Management: Connecting science and management
}

A 10-year science-management partnership has focussed on three key issues within Booderee National Park in eastern Australia: the impacts of fire on native biota; the response of vertebrates to feral animal control, and the control of Bitou Bush. What has been achieved to date and what are the partnership's key ingredients?

Keywords: reserve management, science/management partnership, invasive plant and animal control, fire management, biodiversity conservation

[Typesetter to include Figure 1 here]

Introduction

Well in excess of AU\$12 billion is invested annually in environmental management in Australia (Lindenmayer \& Gibbons 2012). Despite the magnitude of these investments and the importance of assessment for determining return on environmental and conservation investments, it is extraordinary how infrequently the success of environment management programs is quantified - both in Australia (Lindenmayer \& Gibbons 2012) and overseas 
(Muir 2010). Moreover, Fazey (2006) showed that almost all management of natural and other areas is based on the experience of resource managers and not directly on new scientific knowledge and evidence. This was recently underscored by a review by Westgate et al. (2012a) which showed that published examples of true active adaptive management studies of natural resource and biodiversity conservation were extremely rare. That is, published practical cases proved to be uncommon where the iterative feedback loops between scientific research and on-the-ground management had been definitively closed.

Here we describe the development of a strong and enduring scientific research-resource management partnership in Booderee National Park (BNP) in the Jervis Bay Territory, southeastern Australia that we, the partners, hope will improve management capacity in the short, medium and longer term (Box 1). As outlined by other workers, strong collaborations between researchers and managers is critical to improving the practice of ecological management (Gibbons et al. 2008; Burbidge et al. 2011).

BNP is an iconic reserve (Figs 1 and 2) managed conjointly between Parks Australia and the Wreck Bay Aboriginal Community. It supports an array of high profile nationally endangered species such as the Eastern Bristlebird (Dasyornis brachypterus) (Lindenmayer et al. 2009; Baker et al. 2012) (see Figure 3a). BNP also has one of the highest human visitation rates of any national park in Australia; 450 000 visitors annually (Director of National Parks 2012). Like almost all natural areas, there is a suite of major management and conservation challenges in BNP. We outline how a partnership has been forged between managers of BNP and research staff at The Australian National University (ANU) that has attempted to address some of these management challenges. While it is too early to report final results in all aspects of the program, early indications are that the partnership's $10+$ year monitoring program has enabled information derived from ANU research to be shared by Park staff and the Park Board of Management; and this has helped improve some on-the-ground practices. 
Scientific insights also will help guide future management through the forthcoming BNP Management Plan (Director of National Parks 2011) (Box 1).

In this paper, we examine the science-management interaction at BNP associated with three key issues - the impacts of fire on biodiversity, the effectiveness of feral animal control (primarily the control of the Red Fox [Vulpes vulpes]), and the control of the invasive Bitou Bush (Chrysanthemoides monilifera ssp. monilifera). For each issue, we briefly discuss the nature of the problems, the science being used to explore their impacts, and then the conversion of that new science into altered on-the-ground management actions.

\section{[Typesetter to Insert Box 1 about here]}

\section{Background - the ecology and management of Booderee National Park}

BNP is located in the Jervis Bay Territory, $200 \mathrm{~km}$ south of Sydney on the south coast of New South Wales, south-eastern Australia (approximate midpoint is $35^{\circ} 10^{\prime} \mathrm{S}, 150^{\circ} 40^{\prime} \mathrm{E}$ )

(Fig. 2). The area has a temperate maritime climate with an average rainfall of $1240 \mathrm{~mm}$ per year spread relatively evenly over the year. Average minimum and maximum air temperatures for January (summer) are $18-24^{\circ} \mathrm{C}$ and $9-15^{\circ} \mathrm{C}$ for July (winter) (Bureau of Meteorology 2012). The geology of the study area is dominated by Permian ( 260 million year old) sandstone sequences that form part of the southern boundary of the extensive Sydney Basin. Pleistocene ( $<1.6$ million year old $)$ windblown sand dune systems cover the Permian sandstones in parts of BNP. Other geological formations include siltstones and Tertiary-aged alluvial deposits (Cho 1995). 
BNP supports extraordinary patchiness and heterogeneity in vegetation types (ranging from dry heath to warm temperate rainforest) which differ markedly in floristics and structure (Taws 1998). The area also has a well-documented and carefully mapped fire history dating back several decades (Lindenmayer et al. 2008b). In addition, an extensive baiting program for feral predators has been underway for more than a decade in BNP (Roberts et al. 2006).

In 2002, a program commenced to monitor vertebrate biota in BNP. The monitoring entailed the establishment of 110 permanent sites, each of 2 hectares, on which populations of small mammals, arboreal marsupials, birds, reptiles, amphibians and plants have been measured annually to date (i.e., 2002-2012).

Following site establishment and the completion of the first year of surveys for most groups, a major wildfire burned approximately 50\% of BNP in late December 2003 (Figure 2b). Fifty-nine of our permanent sites were burned at varying levels of severity (see Figure 2c). This catalysed a series of studies of post-fire ecological recovery by terrestrial vertebrates (e.g., Lindenmayer et al. 2008a,b,c; Westgate et al. 2012a).

In addition to the 110 permanent monitoring sites, other long-term survey transects have been established as part of individual studies designed to answer particular management problems identified by the managers of BNP. An example is the 34 sites which comprise an experiment designed specifically to quantify the impacts of control efforts for the invasive plant Bitou Bush and test the effectiveness of management practices employed by staff at BNP (see below).

\section{Case examples of links between science and management}

\section{The impacts of fire on biodiversity}

Fire is the predominant form of disturbance in BNP. Two kinds of fire - unplanned fire (wildfire) and prescribed burning - occur in the area; and there is a detailed fire management 
plan for the reserve that identifies fire regimes appropriate for conserving the park's biodiversity, including protecting endangered taxa such as the Eastern Bristlebird (DEWHA 2008). However, at the time of the commencement of the monitoring program in 2002 , the impacts of fire (including prescribed burning) on biodiversity in BNP were poorly known. Indeed, there was considerable concern about the impacts of fire, including prescribed fire, on the persistence of the Eastern Bristlebird (Baker 2000) with some authors suggesting that the species may take up to seven years after a fire to recover to pre-fire levels (Pyke et al. 1995).

Following the 2003 wildfire in BNP, the permanent monitoring sites provided a valuable opportunity to answer a suite of key questions about biodiversity responses to fire. For example, a short-term, cross-sectional study revealed that the bird assemblage had fully recovered within 3-4 years of the 2003 fire (Lindenmayer et al. 2008b). This short-term pattern of recovery included the rapid post-fire recovery of the Eastern Bristlebird (Lindenmayer et al. 2009). One of the key factors influencing the recovery of both the overall bird assemblage and the Eastern Bristlebird was the patchiness of the fire, with faster and more complete recovery (to pre-fire conditions) documented for those sites supporting more unburned areas and biological legacies (sensu Franklin et al. 2000) than those subject to highseverity, uniform fire.

In contrast to the outcomes from the short-term cross-sectional research, a longer term analysis revealed a highly significant relationship between fire history and bird species richness (Lindenmayer et al. 2008b). Fire mapping indicated that the number of fires in any given area of BNP has varied from none to five and the time since the last fire has ranged from four to 35 years. Subsequent data analyses revealed that observed bird species richness was reduced by $9.1 \%$ per site per fire over the past 35 years, irrespective of vegetation type. Hence, observed species richness was significantly lower on more frequently burned sites, particularly those subject to up to five fires since 1974 (Lindenmayer et al. 2008b). For other 
groups such as reptiles and amphibians, there appear to be no discernible major effects of either the 2003 fire or fire history, with vegetation type having the pre-dominant impact on the distribution and/or abundance of species in these groups of vertebrates (Lindenmayer $e t$ al. 2008c; Westgate et al. 2012a).

The results for birds and other groups were reported in the Parks Technical Audit and incorporated into the Draft Management plan which was available for public input (DEWHA 2008). The results also were discussed as part of workshops on fire impacts and decisionmaking in fire management (Driscoll et al. 2010a,b) and then carefully adopted as part of fire management planning in BNP. This led to some important operational changes. First, the new understanding of the relationships between bird persistence and recovery following fire has resulted in a change from uniform prescribed burning of entire compartments of native vegetation to patchy fires across a maximum proportion of a given compartment. Moreover, such prescribed burns typically result in a mosaic of burned and unburned areas (see Figure 2d). Second, in the event of a wildfire, activities like blackout burning in which unburned patches within the boundaries of a fire are subsequently deliberately burned (e.g. see Backer et al. 2004) are avoided in BNP to the extent practicable. Third, based on relationships between fire history and depressed bird species richness (Lindenmayer et al. 2008b), burning in BNP is now typically directed away from those areas which have had many fires in the past $40+$ years.

The draft management plan summarises the ANU/BNP research findings on fire, prescribes a fire management program which takes account of the research findings described above, and prescribes continued research into the ecological impacts of fire, including longterm vegetation changes, post-fire flora and fauna dynamics, and trends in populations of threatened and endangered species (Director of National Parks 2011). 


\section{Feral predator control}

The impact of feral predators, especially the Red Fox (Figure 4a) (but also the Feral Cat [Felis cattus]) on native biota is an issue of significant management concern within BNP. As a result, a poison baiting program to reduce the impact of the Red Fox has been underway in BNP since 1999 and has been widespread and intensive throughout the park since 2003, (Figure 4b) (Roberts et al. 2006; Dexter et al. 2012a).

Since the establishment of the feral animal control program, and particularly its intensification in 2003, there have been substantial increases in populations of some mammals such as the Common Brushtail Possum (Trichosurus vulpecula) and the Longnosed Bandicoot (Perameles nasuta) (Lindenmayer et al. 2008a); although the latter species has exhibited major inter-annual fluctuations in abundance (Dexter et al. 2011; MacGregor et al., unpublished data). In addition, our monitoring work has shown that the Eastern Bristlebird have been found in larger numbers and in more kinds of habitats in BNP (Lindenmayer et al. 2009, unpublished data) than documented in earlier work (e.g. Pyke et al. 1995, Baker 1997, 2000). For example, the Eastern Bristlebird is now found in stands of Swamp Oak Woodland and Shrublands on dune systems where it was previously rarely recorded or absent.

The long-term vertebrate population monitoring data we have gathered provide good evidence of the apparent effectiveness of the intensive control program for the Red Fox in BNP. On this basis, intensified approach to feral animal control in BNP is now well established as a key and ongoing conservation activity recognised formally within the official management plan for the reserve (Director of National Parks 2011). 


\subsection{Some unexpected and potentially perverse outcomes of feral predator control}

At the same time as some species have exhibited marked temporal increases in abundance, probably as an outcome of feral predator control, others have crashed in numbers. The Greater Glider (Petauroides volans) appears to have become extinct within BNP and has not been detected since 2007 (Lindenmayer et al. 2011). Similarly, BNP now (in 2012) supports only very limited numbers of the Common Ringtail Possum (Pseudocheirus peregrinus) (MacGregor et al., unpublished data). This is despite the species being common across many vegetation types in the area just five years previously (Lindenmayer et al. 2008a). The loss of the Greater Glider follows the earlier extinction of the Yellow-bellied Glider (Petaurus australis) in BNP in the late 1980s. The loss of these species is at odds with the conservation charter for BNP which aims to conserve populations of all native species within its boundaries (EPBC Act 1999; Director of National Parks 2011). Indeed, given considerable urban development in the surrounding region, the National Park should provide a reservoir of species and functional habitat to maintain regional biodiversity. It is also important for park managers and scientists to identify the drivers of the declines and/or extinctions - if at all possible - to try to prevent additional future losses of species in BNP.

The underlying reasons for the declines of the Greater Glider and the Common Ringtail Possum remain unclear. There have been active discussions and workshops between BNP and ANU staff in an effort to identify the cause. One possibility is that it has been a perverse (and highly unexpected) outcome of the feral animal control program that altered trophic interactions, with subsequent increasing predation pressure from wide-ranging forest owls.

The potential for unexpected changes in trophic interactions instigated a new modelling study that explored simulated interactions between species in the BNP ecosystem (Dexter et al. 2012b). Indeed, that work suggested that arboreal marsupials such as the Greater Glider 
may indeed be susceptible to altered trophic interactions triggered by baiting for feral predators (Dexter et al. 2012b).

Additional management challenges have begun to emerge in BNP, most likely as a result of the success of feral predator control. One of these has been the 10-fold increase in the numbers of macropods, particularly by the Black Wallaby (Wallabia bicolor) over the past decade (Dexter et al. 2012b). The most appropriate approaches to deal effectively with such a high level of abundance of macropods (and their potential impacts on vegetation cover [see Dexter et al. 2012b)] remains unclear. Given this, a series of new collaborative studies between BNP and ANU has commenced, including an experiment using animal exclosures (Figure 4c) to quantify the impacts on biodiversity of full, partial and no macropod browsing control.

\section{[Typesetter to Insert Figure4 about here]}

\section{Bitou Bush}

The invasive plant, Bitou Bush is a serious problem in parts of BNP as it is elsewhere throughout coastal eastern Australia (Carolin \& Clarke 1991). The extensive areas of Bitou Bush in BNP are in fact some of the largest infested in southern New South Wales (Figure 4a), making some treatment methods like hand pulling and spot spraying of individual plants alone impractical. Bitou Bush control in BNP comprises a series of treatments. These involve Ultra Low Volume (ULV) aerial spraying of herbicide in winter (when native plant growth is slowest) (Toth et al. 1993), followed by prescribed burning of the treated areas and then a follow-up repeat winter application of herbicide to kill Bitou Bush plants germinating after fire (Vranjic \& Groves 1996) (Figure 4b). 
Although it has been assumed, based on a limited range of glasshouse and field tests, that ULV spraying in June does not have adverse impacts on most native species, the longterm effectiveness of the treatment program of Bitou Bush and impacts on native plants and animals are poorly understood (Adair et al. 2012). Given this lack of knowledge, it was agreed by ANU researchers and staff from BNP that an experiment should be established to determine the effectiveness of control efforts including estimating the separate effects of the different sub-treatments on not only Bitou Bush but also native plants and birds, small mammals and reptiles.

The experiment that commenced in 2007 targets two vegetation types where infestations of Bitou Bush is a particular problem-Swamp Oak (Casuarina glauca) woodland and forest (dominated by Blackbutt (Eucalyptus pilularis) and Bangalay (E. botryoides)). The experiment comprises 34 sites and takes advantage of the reality of invasive species control in BNP where logistical and human safety issues mean that only some areas receive the complete spray-burn-spray regime and others are subject to only parts of it. In addition, some of the 110 sites in the long-term monitoring study provide additional external control sites such as those in Casuarina woodland and Blackbutt forest where there is no Bitou Bush.

Preliminary results from the Bitou Bush experiment suggest that spraying followed by burning was successful in reducing the number of Bitou Bush plants in treated areas (D. Lindenmayer et al., unpublished data). The number of native plant species was also dramatically reduced by the ULV spraying and burning treatments, but then recovered rapidly within 2-3 years. The treatment protocol also appears to have no lasting effects on almost all species of small mammals, reptiles and birds.

The most major negative effects of Bitou Bush treatment on plant and animal biota occurred with two or more fires in rapid succession ( $<5$ years) in areas subject to Bitou Bush 
treatment—-such as when an unplanned fire occurs soon after prescribed burning. Under such conditions, the ground and understorey vegetation layers became greatly simplified and are dominated by Bracken (Pteridium esculentum) whereas this cosmopolitan species of fern did not become dominant in areas where repeated burning did not occur (D. Lindenmayer et al., unpublished data). This phenomenon is probably due to intense post-fire browsing by the Black Wallaby (Dexter et al. 2012b).

The results of the experiment show that that the current approach to control at BNP appears to be effective. However, it is important to limit the number of fires that occur in areas subject to Bitou Bush control, and particularly repeated fires within 5 years.

Discussions between ANU staff and the managers of BNP are now well advanced about how the management practices used to control Bitou Bush will be altered in the future. One possible alteration to management practices that has been canvassed to date is to temporarily cover individuals of those species of plants of conservation concern during aerial spraying operations. These are species which our data analyses indicate have some sensitivity to spraying.

\section{[Typesetter to Insert Figure 5 about here]}

\section{General Discussion}

Working relationships between research scientists and resource managers are important (Gibbons et al. 2008, (Burbidge et al. 2011) but they are often difficult and unsuccessful (Rudd 2011). This is, in part, because these two sets of professionals have different reward systems, objectives, and sub-cultures (Gibbons et al. 2008). However, a strong and enduring science-management partnership has been established between ANU researchers and the managers of BNP. Scientific information from a long-term monitoring program and allied projects has been used to underpin changes in on-the-ground practical natural resource 
management, particularly the management of fire. Changes to management processes to improve and integrate research findings into management have been embraced. These changes include annual reporting by ANU staff to the Park Board of Management and the Park Technical Audit, and extensive verbal and written ANU input into Park Management Plans to guide future management. In turn, a commitment to ongoing research and monitoring that is outlined into the Management Plan will provide further insights to guide future management. This science-management partnership has helped to elevate BNP to being rated among the best managed parks in Australia (WWF Australia 2008).

We recognise that the monitoring program, predator baiting program, and the Bitou Bush experiment do not qualify as true active adaptive management studies in which different management options are tested under strict experimental conditions and there are tight feedback loops between: (a) the setting of management options, monitoring and scientific study to test the efficacy of those options, and (b) management action to implement the best option/s (reviewed by Westgate et al. 2012a). Active adaptive management is widely regarded as "the gold standard" of applied research-resource management integration (Walters 1986; Walters \& Holling 1990; Nichols \& Williams 2006). However, a recent review (Westgate et al. 2012a) suggests that "real-world" examples of true active adaptive management studies are rare worldwide. Nevertheless, it is clear there are strong interrelationships between the science being conducted at BNP and the application of that science is improving resource management practices.

We suggest there are several key reasons why the science-management partnership has been enduring and successful at BNP. Notably, many of these reasons are strongly congruent with the factors which Burbidge et al. (2011) suggests are important to the success of the research-management cycle in natural resource management and biodiversity conservation. 
A. A strong culture of science in reserve management. There is a strong science culture among several of the senior managers at BNP - a characteristic not always prevalent among the reserve management fraternity both in Australia and overseas (Fazey et al. 2006). Senior managers at BNP are post-graduate trained and understand the importance of scientific evidence to inform policies and management of natural resources. Indeed, these managers have lead-authored or coauthored a number of scientific articles based, in part on the monitoring data gathered at BNP (e.g. Lindenmayer et al. 2008a, 2009; Dexter et al. 2011, 2012a,b; MacGregor et al. 2013). Moreover, park staff are on the supervisory panel of several post-graduate students working on key projects within BNP to ensure these studies are relevant to management (sensu Russell-Smith et al. 2003) as well as scientifically robust.

B. Co-location of staff. An ANU staff member (CM) is located full-time at park headquarters within BNP. This has facilitated the transfer of knowledge and results as well as data sharing. It has also fostered a conjoint understanding of the requirements of scientific research on the one hand and management and policy demands on the other. In addition, the co-location of staff has catalysed meetings and exchanges of ideas, such as field days and writing workshops (e.g. Driscoll et al. 2010a,b) designed to help improve resource management in BNP.

\section{Provision of funding to facilitate the science-management partnership. Parks} Australia has provided funding to facilitate the partnership between ANU and BNP staff. These funds contribute to $40 \%$ of the salary of an ANU staff member who is based permanently at BNP as well as support for the maintenance of infrastructure on the long-term monitoring sites. This funding has assisted to leverage other resources and expand the range of questions that can be addressed, including 
through two MSc and five $\mathrm{PhD}$ projects, thereby adding substantial value to the initial Parks Australia investment.

D. Continuity of staff. Many of the management staff at BNP have held long-term appointments within the reserve. The same has occurred with the ANU staff member based permanently within BNP. This has ensured there is a strong level of trust, mutual respect and productive working relationships to have developed over the past decade. The long-term nature of the science-management partnership also has ensured sufficient time to enable robust research and monitoring programs to progress to a stage where high quality data can be gathered and subsequently analysed and published in the peer-reviewed scientific literature.

E. Conjoint identification of knowledge gaps. The ensuring science-management partnership at BNP has continued to respond to new insights and discoveries over the past decade. This has been demonstrated through the identification, for example, of the possible consequences of the intensification of feral predator control which, in turn, led both to detailed modelling to further explore the issue (Dexter et al. 2012a) and a major experimental study to empirically quantify the possible effects of large numbers of macropods (see Figure 4c). Similarly, the recent results of work on the effectiveness of the Bitou Bush control program as well as its effects on nontarget taxa have begun to be discussed in detailed between staff at BNP and ANU researchers with the aim of modifying and improving protocols in the future.

F. Trust and support in the role of science in guiding management of the Park by the owners of the land, the Wreck Bay Aboriginal Community, as reflected in Community members involvement in the key programs outlined in this paper ( 3 of 8 staff in the Natural Resource Management unit of the Park are Community 
members), and the research, monitoring and adaptive processes prescribed in the Parks Management Plan (Director of National Parks 2011).

It is a truism to note that managing natural resources, including those in formally protected areas like BNP, is difficult and characterised by many complex problems. Good science, receptive and agile management and well developed and long-term sciencemanagement partnerships are needed to identify (and then implement) solutions to complex problems (Gibbons et al. 2008). The science-management partnership at BNP has attempted to overcome many of the major impediments which might otherwise thwart attempts to better link research and the practice of ecological management (Burbidge et al. 2011). Both parties view the partnership as a critical important vehicle to ensure that the management of one of Australia's iconic protected areas continues to improve in response to new scientific information and is as good and effective as it can possibly be.

\section{Acknowledgments}

We thank the people of the Wreck Bay Aboriginal Community for support with this project and the Australian Research Council, Parks Australia, the National Environmental Research Program (NERP) and the Terrestrial Ecosystem Research Network (TERN) for funding. The work reported here could be completed only because of the extraordinary efforts of key field staff including Darren Brown, Mason Crane, Damian Michael, Sachiko Okada, Lachlan McBurney, David Blair, Rebecca Montague-Drake, Claire Shepherd and Geoff Kay. We also thank the enduring volunteers from the Canberra Ornithologists Group (COG) for their wonderful efforts; particularly Bruce Lindenmayer, Jenny Bounds, Martin Moffatt, Terry Munro and Peter Roberts. Finally, we thank those undertaking research studies in BNP including Martin Westgate, Felicia Pereoglou, Ingrid Stirnemann, Claire Foster, Nelida 
Villasenor, Don Driscoll, Sam Banks, Phil Gibbons and Maxine Piggott. An anonymous referee provided helpful comments that improved an earlier version of the manuscript.

\section{References}

Adair R. J., Morley T. and Morin L. (2012) Chrysanthemoides monilifera (L.) T. Norl. - bitou bush and boneseed. In: Biological Control of Weeds in Australia (eds M. Julien, R. McFadyen and J. Cullen) pp. 170-1183. CSIRO Publishing, Melbourne, Australia.

Backer, D. M., Jensen, S. E. and McPherson, G. R. (2004) Impacts of fire suppression activities on natural communities. Conservation Biology 18, 937-944.

Baker J., Bain D., Clarke J. and French K. (2012) Translocation of the Eastern Bristlebird 2: applying principles to two case studies. Ecological Management \& Restoration 13, 159165.

Baker J. R. (2000) The Eastern Bristlebird: cover dependent and fire sensitive. Emu 100, 286298.

Burbidge A. H., Maron M., Clarke M. F., Baker J., Oliver D. L. and Ford G. (2011) Linking science and practice in ecological research and management: How can we do it better? Ecological Management \& Restoration 12, 54-60.

Bureau of Meteorology (2012) Climate statistics for Australian locations: Summary statistics Jervis Bay. Available from URL: http://www.bom.gov.au/climate/averages/tables/cw_068034.shtml.

Carolin R. and Clarke P. (1991) Beach Plants of South Eastern Australia. Sainty and Associates, Sydney.

Cho G. (1995) The Jervis Bay environment. In: Jervis Bay: a place of cultural, scientific and educational value (eds G. Cho, A. Georges and R. Stoutjesdijk) pp. 3-8. Australian Nature Conservation Agency, Canberra. 
Debus S. J. S. (1997) A survey of the raptors of Jervis Bay National Park. Australian Birds 30, 29-44.

Debus S. J. S., Davies J. N. and Hollands D. (2009) The Owls of Australia: A Field Guide to Australian Night Birds. Envirobook in association with Birds Australia, Sydney, Australia. DEWHA (2008) Booderee National Park. Fire Management Program 2008. Booderee National Park, Park Services Team, Department of the Environment, Water, Heritage and the Arts (DEWHA), Jervis Bay Territory.

Dexter, N., Hudson, M., Carter, T., MacGregor, C.I. (2011). Habitat-dependent population regulation in an irrupting population of long-nosed bandicoots (Parameles nasuta). Austral Ecology 36, 745-754.

Dexter N., Hudson M., James S., MacGregor C. and Lindenmayer D. B. (2012a) Unintended consequences of intensive fox control in an Australian forest: overabundant wallabies and vegetation change. PLOS One In review.

Dexter N., Ramsay D. S. L., MacGregor C. and Lindenmayer D. B. (2012b) Predicting ecosystem wide impacts of wallaby management using a fuzzy cognitive map. Ecosystems doi: 10.1007/s10021-012-9590-7.

Director of National Parks (2011) Booderee National Park Draft Management Plan 2011 2021. Director of National Parks, Canberra.

Director of National Parks (2012) Annual Report 2011-12. Director of National Parks, Canberra

Driscoll D. A., Lindenmayer D. B., Bennett A. F., Bode M., Bradstock R. A., Cary G. J., Clarke M. F., Dexter D., Fensham R., Friend G., Gill M., James S., Kay G., Keith D. A., MacGregor C., Possingham H. P., Russell-Smith J., Salt D., Watson J. E. M., Williams R. J. and York A. (2010a) Resolving conflicts in fire management using decision theory: asset-protection versus biodiversity conservation. Conservation Letters 3, 215-223. 
Driscoll D. A., Lindenmayer D. B., Bennett A. F., Bode M., Bradstock R. A., Cary G. J., Clarke M. F., Dexter D., Fensham R., Friend G., Gill M., James S., Kay G., Keith D. A., MacGregor C., Russell-Smith J., Salt D., Watson J. E. M., Williams R. J. and York A. (2010b) Fire management for biodiversity conservation: Key research questions and our capacity to answer them. Biological Conservation 143, 1928-1939.

Fazey I., Fazey J. A., Salisbury J. G. and Lindenmayer D. B. (2006) The nature and role of experiential knowledge for environmental conservation. Environmental Conservation 33, $1-10$.

Franklin, J. F., Lindenmayer, D. B., MacMahon, J. A., McKee, A., Magnuson, J., Perry, D.A., Waide, R. and Foster, D.R. (2000). Threads of continuity: ecosystem disturbances, biological legacies and ecosystem recovery. Conservation Biology in Practice 1, 8-16.

French K. and Zubovic A. (1997) Effect of the weed Chrysanthemoides monilifera (bitou bush) on bird communities. Wildlife Research 24, 727-735.

Gibbons P., Zammit C., Youngentob K., Possingham H. P., Lindenmayer D. B., Bekessy S., Burgman M., Colyvan M., Considine M., Felton A., Hobbs R., Hurley C., McAlpine C., McCarthy M. A., Moore J., Robinson D., Salt D. and Wintle B. (2008) Some practical suggestions for improving engagement between researchers and policy-makers in natural resource management. Ecological Management \& Restoration 9, 182-186.

IUCN - The World Conservation Union (1994) Guidelines for protected area management categories. IUCN, Switzerland.

Lindenmayer D. B. and Gibbons P. (Eds) (2012) Biodiversity Monitoring in Australia. CSIRO Publishing, Melbourne.

Lindenmayer D. B., Macgregor C., Welsh A. W., Donnelly C. F., Crane M., Michael D., Montague-Drake R., Cunningham R. B., D. B., Fortescue M., Dexter N., Hudson M. and 
Gill A. M. (2008a) Contrasting mammal responses to vegetation type and fire. Wildlife Research 35, 395-408.

Lindenmayer D. B., MacGregor C., Wood J. T., Cunningham R. B., Crane M., Michael D., Montague-Drake R., Brown D., Fortescue M., Dexter N., Hudson M. and Gill A. M. (2009) What factors influence rapid post-fire site re-occupancy? A case study of the endangered Eastern Bristlebird in eastern Australia. International Journal of Wildland Fire 18, 84-95.

Lindenmayer D. B., Wood J. T., Cunningham R. B., MacGregor C., Crane M., Michael D., Montague-Drake R., Brown D., Muntz R. and Gill A. M. (2008b) Testing hypotheses associated with bird responses to wildfire. Ecological Applications 18, 1967-1983.

Lindenmayer D. B., Wood J. T., MacGregor C., Michael D. R., Cunningham R. B., Crane M., Montague-Drake R., Brown D., Muntz R. and Driscoll D. (2008c) How predictable are reptile responses to wildfire? Oikos 117, 1086-1097.

Lindenmayer D. B., Wood J. T., McBurney L., MacGregor C., Youngetob K. and Banks S. C. (2011) How to make a common species rare: A case against conservation complacency. Biological Conservation 144, 1663-1672.

Ludwig D., Mangel M. and Haddad B. (2001) Ecology, conservation and public policy. Annual Review of Ecology and Systematics 32, 481-517.

MacGregor, C., Wood, J.T., Dexter, N. and Lindenmayer,, D.B. (2013). Home range size and use by the long-nosed bandicoot (Perameles nasuta) following fire. Australian Mammalogy (in re-review).

Muir M. J. (2010) Are we measuring conservation effectiveness? Report to Conservation Measures Partnership. Available at URL: www.conservationmeasures.org.

Nichols J. D. and Williams B. K. (2006) Monitoring for conservation. Trends in Ecology and Evolution 21, 668-673. 
Pyke G., Saillard R. and Smith R. (1995) Abundance of Eastern Bristlebirds in relation to habitat and fire history. Ети 95, 106-110.

Roberts M. W., Dexter N., Meek P. D., Hudson M. and Buttemer W. A. (2006) Does baiting influence the relative composition of the diet of foxes? Wildlife Research 33, 481-488.

Rudd M. A. (2011) How research-prioritization exercises affect conservation policy. Conservation Biology 25, 860-866.

Russell-Smith J., Whitehead P. J., Cook G. D. and Hoare J. L. (2003) Response of Eucalyptus-dominated savanna to frequent fires: lessons from Munmarlary 1973-1996. Ecological Monographs 73, 349-375.

Sheean V. A., Manning A. D. and Lindenmayer D. B. (2011) An assessment of scientific approaches towards species relocations in Australia. Austral Ecology 37, 204-215.

Taws N. (1998) Fire and vegetation management in Jervis Bay Territory. Environment Australia, Canberra.

Toth J., Milham P. and Nazer C. (1993) Aerially applied herbicides selectively control Bitou bush growing in communities of indigenous plants on sand dunes. Proceedings of the 14th Asian Pacific Weeds Conference, Vol. 2, pp. 67-71.

Vranjic J. A. and Groves R. H. (1996) Revegetation of coastal habitats invaded by Bitou bush. In: Second Australian Native Seed Biology for Revegetation Workshop Proceedings (eds S. M. Bellairs and J. M. Osborne) pp. 221-224. Canberra.

Walters C. J. (1986) Adaptive Management of Renewable Resources. Macmillan Publishing Company, New York.

Walters C. J. and Holling C. S. (1990) Large scale management experiments and learning by doing. Ecology 71, 2060-2068.

Westgate M., Likens G. E. and Lindenmayer D. B. (2012a) A systematic review of Adaptive Management. Biological Conservation in press 
Westgate M., Driscoll D. and Lindenmayer D. B. (2012b) Can the intermediate disturbance hypothesis and information on species traits predict anuran responses to fire? Oikos 121, $1516-1524$.

WWF Australia (2008) Building Nature's Safety Net: Top 10 reserves of the first decade of the National Reserve System. Available at URL:

http://awsassets.wwf.org.au/downloads/bi028 top10 reserves_of national_reserve syste $\underline{\mathrm{m}}$ 15nov06.pdf. 


\section{Box 1. Input into the management planning process at BNP.}

Like Kakadu and Uluru Kata Tjuta National Parks, BNP is an Aboriginal-owned Commonwealth reserve declared under the Environment Protection and Biodiversity Conservation Act 1999. The objectives of the Act are to protect the environment, and especially matters of national environmental significance such as endangered species. The Act requires reserves to be managed in accordance with a management plan. BNP has a highly prescriptive draft management plan that is being prepared by the Park Board of Management (Director of National Parks 2011). IUCN management principles broadly guide the plan including the key objective of the Park, namely, to conserve its biodiversity and cultural heritage (IUCN 1994; Director of National Parks 2011).

The Park Board is comprised by a majority of Wreck Bay Aboriginal Community members (7 of 13) but also has a scientific representative (Director of National Park 2011). The Park has 27 employees, of which approximately half are members of the Wreck Bay Community. The park has a strong scientific focus, with a Natural Resource Management Section consisting of 8 employees which includes a full-time employee of the Australian National University, supplemented currently by 7 PhD students (Director of National Parks 2012).

The draft plan has been significantly influenced by the research/management partnership with ANU, particularly in the areas of research, monitoring and reporting. Research findings were regularly reported to (and discussed in) the Park Board while they were drafting the management plan, and extensive ANU input was made into Park Management Plans to guide future management. The Plan summarises the ANU/BNP research findings on fire, prescribes a fire management program which takes account of the research findings, and prescribes continued research into the ecological impacts of fire, including long-term vegetation 
changes, post-fire flora and fauna dynamics, and trends in populations of threatened and endangered species (Director of National Parks 2011).

The Plan also includes procedures to maintain scientist-management practice relationships including a requirement for annual reporting by ANU staff to the Park Board of Management and the Park Technical Audit - and spells out the role of ongoing research, specifying future directions for priority research programs. These innovations can be seen as evidence that the managers of BNP have put considerable thought and effort into the development of approaches to close the research-management loop. This approach is based on the principle that without high quality ecological research, monitoring and reporting, it is not possible to adapt and improve management for biodiversity conservation. 


\section{FIGURE CAPTIONS.}

Figure 1. Booderee National Park is a 6,500 ha coastal park located in the Jervis Bay

Territory, south-eastern Australia. It has a diversity of species (over 460 native plants and94 terrestrial animals) due in part to the wide range of habitats found in the area-including coastal cliffs and heaths, sandy beaches and rock platforms, mangroves and ocean, swamps, lakes and forests. (Photo David Lindenmayer).

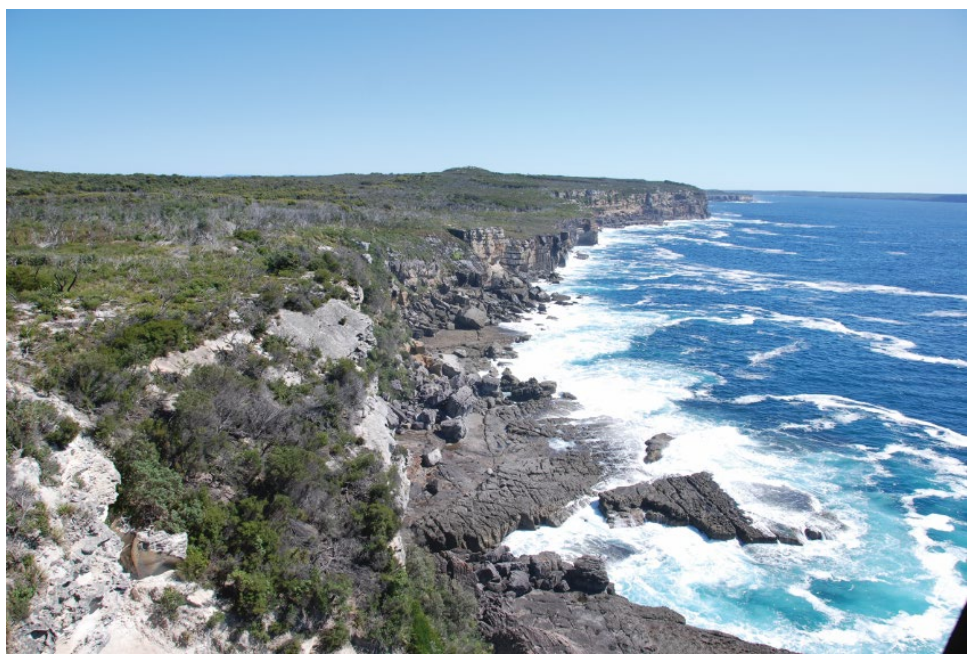

Figure 2. Booderee National Park showing the location of permanent field sites that have been monitored for plants and vertebrates since 2002 (Map courtesy Clive Hilliker).

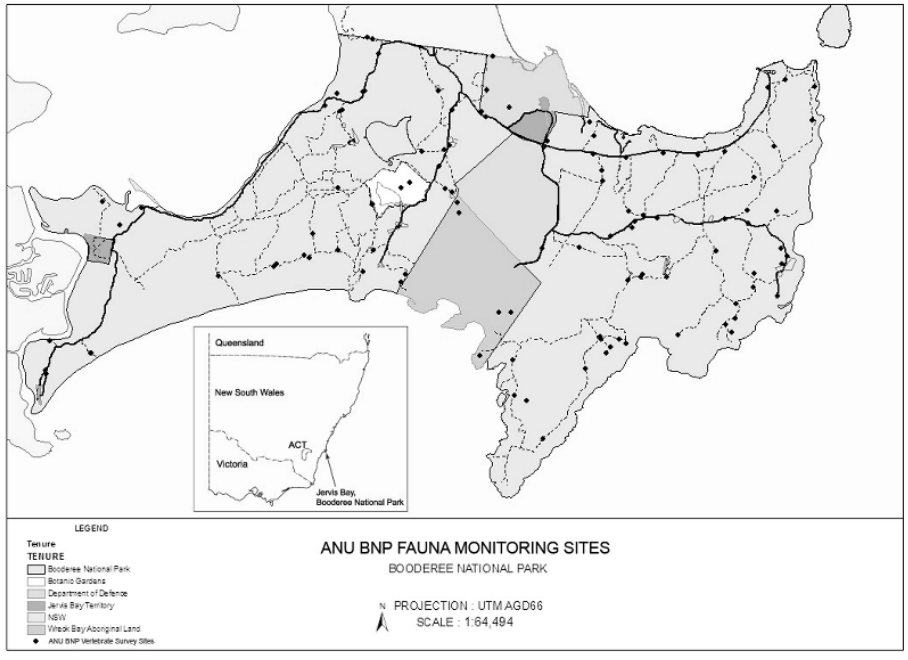


Figure 3. (a) Eastern Bristlebird and endangered species of considerable conservation concern for which BNP represents an important stronghold (photo by Julian Robinson). (b) The 2003 fire burning part of BNP (photo Martin Fortescue). (c) Post-fire surveys and trapping infrastructure at a permanent monitoring site (photo David Lindenmayer). (d)_An area subject to prescribed burning three years previously showing an unburned patch and known to support a pair of breeding Eastern Bristlebirds (photo David Lindenmayer).
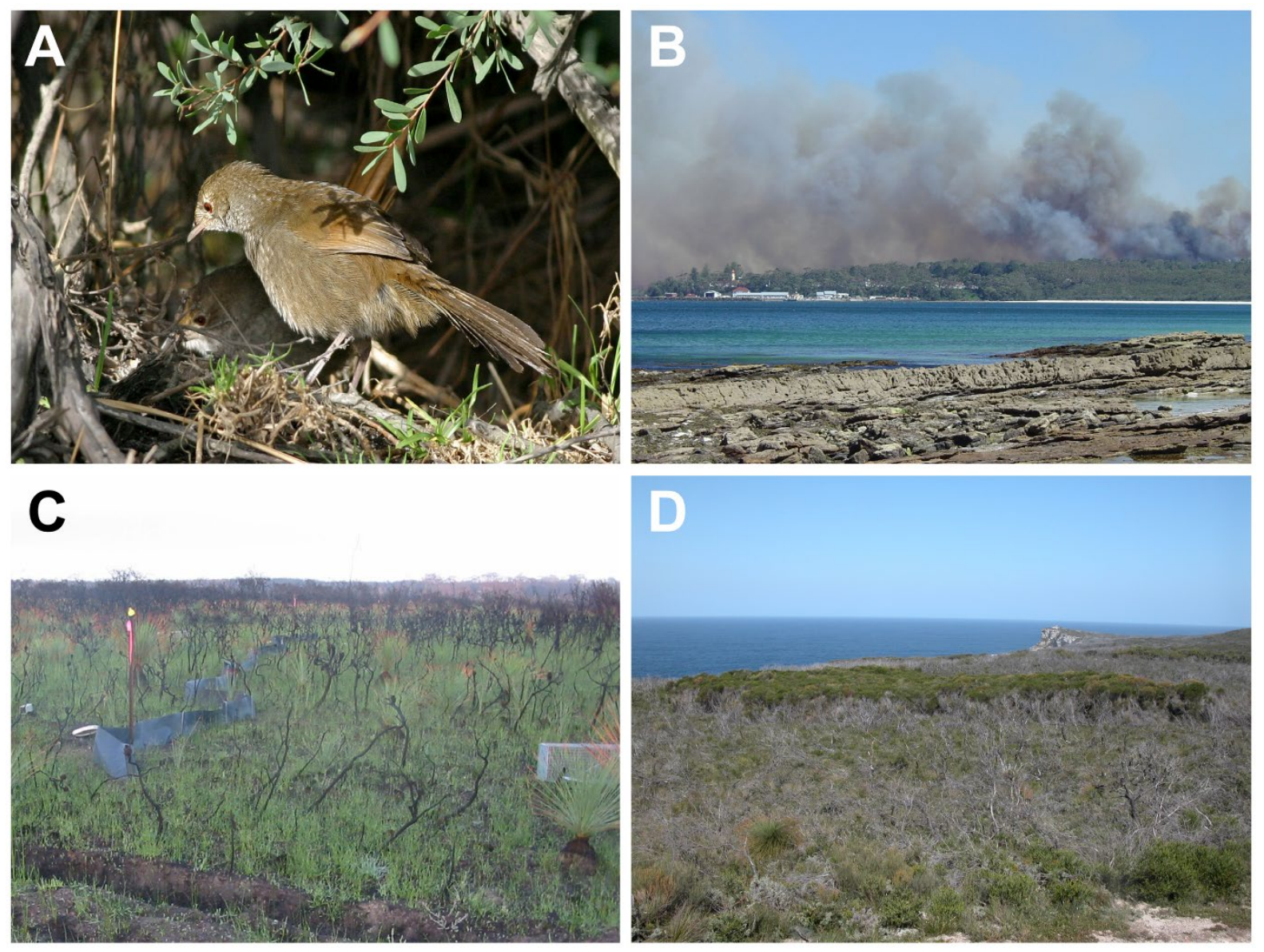

Figure 4. (a). The Red Fox - a species of feral predator targeted for control using an intensive and systematic poison baiting program throughout Booderee National Park (photo Graeme Chapman). (b). A station where baits are laid every month for feral animal control (photo Nick Dexter). (c) A newly established exclosure designed to test for interactions between fire and control of browsing by macropods on vegetation cover, plant species richness and a range of vertebrate and invertebrate groups (photo Claire Foster) 

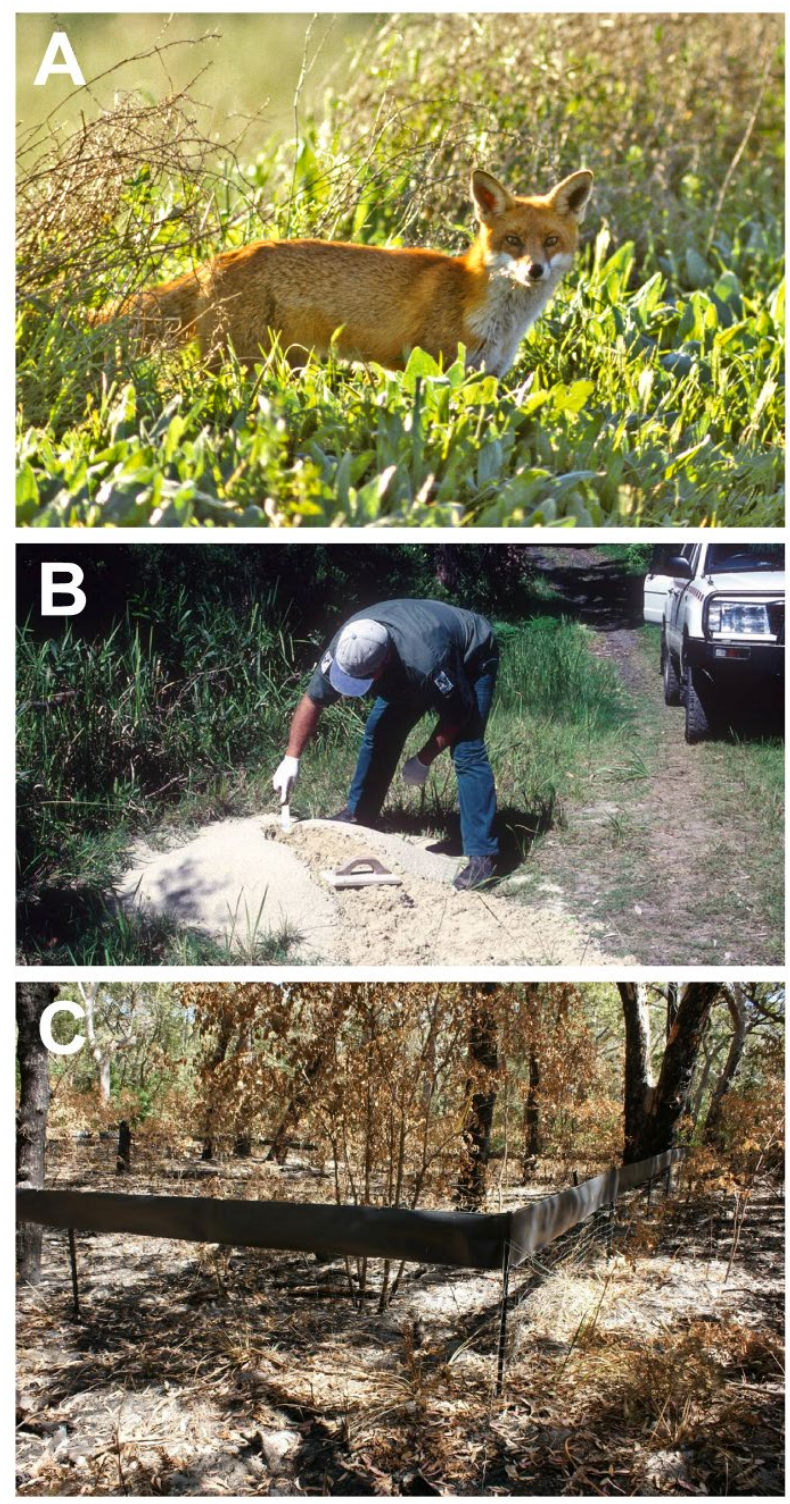

Figure 5. (a) A monitoring site heavily infested by Bitou Bush. (b) A monitoring site immediately after spraying and burning treatments to control Bitou Bush (photos Chris MacGregor).

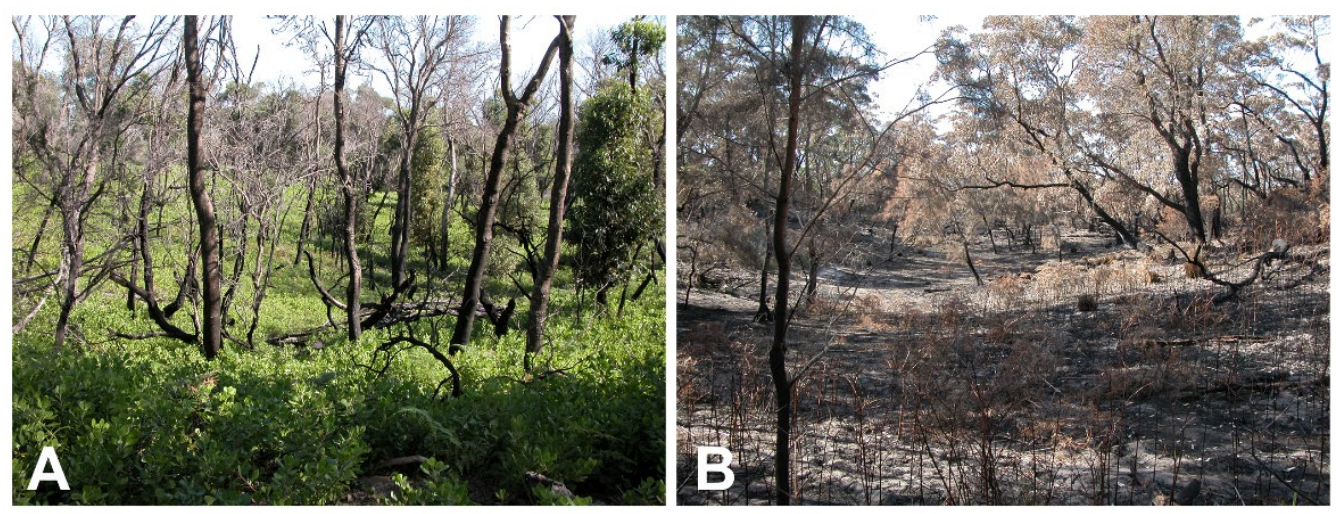

